- A complete OUTLINE OF FRACTURES INCLUDING FRACTURES OF THE SKULL.'-By J. Grant Bonnin, M.B., B.S. (Melbourne), F.R.C.S. (Eng.) Third Edition. 1951. William Heinemann, London. Pp. xiv plus 671. With illustrations. Price, $42 s$.

IN this the third edition of Mr. Bonnin's treatise on fractures, most of the features that made this book so very welcome to the students in particular and to surgeons in general have been preserved. New material, in view of recent knowledge and practice, has been introduced wherever it was found necessary. This includes, for example, a chapter on klintscher nail technique, considerable new material on injuries about the ankle joint, injuries of the face and jaw the operative treatment of finger and hand injuries, and the uses of the newer antibiotics.

This book has already made a name for itself. Unlike some other well-known treatises on the subject, it is adequate without being exhaustive. Its style is direct and straightforward and it avoids on the whole dwelling on the personal likes and dislikes of the author. The illustrations are very well produced and help the reader in following and understanding the text.

We have no doubt that this book would prove extremely popular and be useful to the students and even to surgeons interested in the subject.

\section{A. K. B.}

THORACIC SURGERY.-By Richard H. Sweet, M.D. 1950. W. B. Saunders Company, Philadelphia and London. Pp. xx plus 345, with 155 Illustrations. Price, 60s. net

THORACIC.surgery has advanced in rapid strides during the course of last 10 years and has now established itself as a well-recognized speciality. It is attracting an increasing number of the younger group of surgeons and its scope and usefulness show signs of enlargement almost every day. For example the surgery of congenital or even acquired heart diseases and the surgery of the diaphragmatic abnormalities are of recent origin but have already established themselves. There was however no standard book on this subject to which one could refer in case of necessity and we therefore particularly welcome Dr. Sweet's book. It supplies a long-felt want and does so in a manner worthy of the great name of the author. It is adequate without being exhaustive and in about 350 pages contains all the necessary knowledge of this special branch of surgery.

The book is essentially practical, the operative details are clearly written and the finer points of technique well emphasized. A very important feature of the book is the profuse number of illustrations it contains. These, some of which are in colour, are from the pen and brush of Dr. T. R. Arroyo and many were sketched at actual operative sessions. They are of a very high standard, lucid, clear and help the reader in understanding the operative and anatomical details There are a number of 3 dimensional diagrams of the segmental anatomy of the lungs and its constituents which impress one particularly.

Dr. Sweet has done a lot of original work on œsophageal resection and therefore this part of the book is more comprehensive than the rest. There is a chapter on abdominal operations through the thoracic approach and another on the surgery of the diaphragm both containing all the latest advances in this branch of surgery.

Altogether this is a book which is extremely well written and illustrated. It contains a host of practical informations and should be welcome not only to the specialist but also to general surgeons interested in upper abdominal surgery.

A. K. B.
CURRENT THERAPY, 1951.-Edited by Howard F. Conn, M.D. Published by W. B. Saunders company, Philadelphia and London. Pp. xxxli plus 699. Price, 60s.

THIs book brings to the physician the latest approved methods of treatment in America. One editor and 12 consulting editors, specialists in at least as many subjects, have collaborated in putting together contributions from 275 writers in 16 sections of a book of 699 plus xxxii double-column pages.

The presentation is a perfect example of the separation of the essential from the non-essential : complete freeing of sound grain from chaff. Considered opinion is available on newer treatments like the treatment of syphilis, sprue, paralysis agitans, motion sickness and allergy. One notices that benadryl still holds a place in the treatment of allergy and is indicated for 22 morbid states in the index.

Some treatments could be fuller; for instance, malario therapy could be mentioned in pemphigus.

The paper, printing and binding are very good. On the binding a picture of the Western Hemisphere gilded by the rising sun which has set in Europe, is worthy of mention because of its artistic value alone.

The price, 60 s., could perhaps be lower now that the publication is to be an annual production. Otherwise, it will come between the physicians in the East and the publishers.

An excellent publication.

S. D. S. G

CONTRACEPTIVE TECHNIQUE.-By Helena Wright, M.B., B.S. (Lond.), with the assistance of H. Beric Wright, M.B., B.S. (Lond.). 1951. Published by J. and A. Churchill Ltd., 104, Gloucester Place, London, W.1. Pp. x plus 69. With 16 illustrations. Price, 68.

THIs little book, of 69 plus $x$ pages, supplies an urgent demand.

It should be particularly welcome in India where family planning is being considered seriously by the intelligentsia at present. Such a step, however, is likely to reduce the $1 \mathrm{Q}$. of the country if the planning is practised by the intelligentsia alone. Means must be devised to check the overgrowth of the masses. This booklet devotes a chapter to such means and also supplies the information that the necessary materia and advice, for the Tropical (Primitive) countries, can be obtained from:-

The Secretary,

International Committee on Planned Parenthood, 69, Eccleston Square,

London, S.W.1.

S. D. S. G.

CANCER : WHERE WE STAND.-By Sidney RuSS, C.B.E.; D.Sc., F.Inst.P. With a Foreword by The Right Hon. Lord Horder, G.C.V.O., M.D., F.R.C.P. 1950: Published by Oxford University Press, Geoffery Cumberlege, London, New York, Toronto. Pp. XV plus 192. Illustrated. Price, 10s. 6d.

THIs little book is an exposition of the problem of cancer by a physicist who has been long associated with researches on it. In it are given several aspects 